\title{
Can the nitrification inhibitor DCD decrease nitrous oxide emissions from slurry applied to grassland?
}

E Cahalan $^{1,2}$, K G Richards ${ }^{1}$, C Mueller ${ }^{2}$, M I Khalil ${ }^{1}$, C Watson ${ }^{3}$, R Laughlin ${ }^{3}$, D Hennessy ${ }^{4}$, D Devaney ${ }^{1}$

${ }^{1}$ Teagasc, Johnstown Castle, Co. Wexford, Ireland, ${ }^{2}$ University College Dublin, Dublin, Ireland, ${ }^{3}$ AFBI, Belfast, Ireland,

${ }^{4}$ Teagasc, Moorepark, Co. Cork, Ireland

Email: enda.cahalan@teagasc.ie

Introduction In Ireland, the Kyoto Protocol sets a target to reduce greenhouse gas emissions to within $13 \%$ of 1990 level by 2012. Currently agriculture accounts for $26 \%$ of total emissions and of this figure $36 \%$ is due to trace gas emissions from the soil mainly in the form nitrous oxide $\left(\mathrm{N}_{2} \mathrm{O}\right)$. Landspreading of cattle slurry adds the trace gases $\mathrm{N}_{2} \mathrm{O}, \mathrm{CH}_{4}$ and $\mathrm{CO}_{2}$ to the atmosphere in varying quantities, depending on the application method and climatic conditions at the time of application. The nitrification inhibitor Dicyandiamide (DCD) has been reported to reduce denitrification of excess nitrate within the soil by up to $73 \%$ (Di and Cameron, 2006). Dennis et al. (2008) reported DCD reduced $\mathrm{N}_{2} \mathrm{O}$ emissions from poorly drained Irish soils receiving urine. Little research has been conducted on the efficacy of DCD in reducing emissions associated with landspreading of slurry. The objective of this research was to investigate the effect of DCD in reducing $\mathrm{N}_{2} \mathrm{O}$ emissions following landspreading of slurry using band spreading and splash plate.

Materials and methods There were 5 treatments, with two spreading methods 1. Splashplate (SP) and 2. Bandspread (BS) both \pm DCD and a control. The experiment was conducted on an imperfectly drained fine loam in Johnstown Castle, Wexford arranged in a randomised block design with 6 replicates per treatment. Cattle slurry was applied at a rate of $33 \mathrm{~m}^{3}$ $\mathrm{ha}^{-1}$ in March, June and October 2009, which are typically important dates for slurry application before/after winter and after first cut silage. DCD was mixed with the slurry at a rate of $15 \%$ of the slurry $\mathrm{NH}_{4}-\mathrm{N}$ content prior to application. Gases $\left(\mathrm{N}_{2} \mathrm{O}, \mathrm{CH}_{4}\right.$ and $\left.\mathrm{CO}_{2}\right)$ were collected over a 25 minute period using stainless steel chambers $(0.4 \mathrm{x} 0.4 \mathrm{~m})$ placed on water filled permanent collars. The head gas samples were analysed in the laboratory using gas chromatography. Measurements were made frequently over 1 month after slurry application. The treatments were tested for statistical differences using the GLM procedure in SAS v. 9.1, the factors being spreading method, slurry and DCD.

\section{Results}

The daily $\mathrm{N}_{2} \mathrm{O}$ fluxes and the cumulative flux from the March applied slurry \pm DCD are presented in figure 1 . For splashplate applied cattle slurry receiving DCD reduced cumulative emissions from 110 to $42 \mathrm{~g} \mathrm{~N} \mathrm{ha}^{-1}$. For bandspread slurry $\mathrm{N}_{2} \mathrm{O}$ emissions were decreased from 112 to $60 \mathrm{~g} \mathrm{~N}^{-1}$. Overall the cumulative $\mathrm{N}_{2} \mathrm{O}$ emissions were low after the spring applied slurry. The mean temperature at the site was $7.5^{\circ} \mathrm{C}$ during the sampling period and there was a total rainfall of $55.2 \mathrm{~mm}\left(\operatorname{avg} 1.6 \mathrm{~mm} \mathrm{~d}^{-1}\right)$.

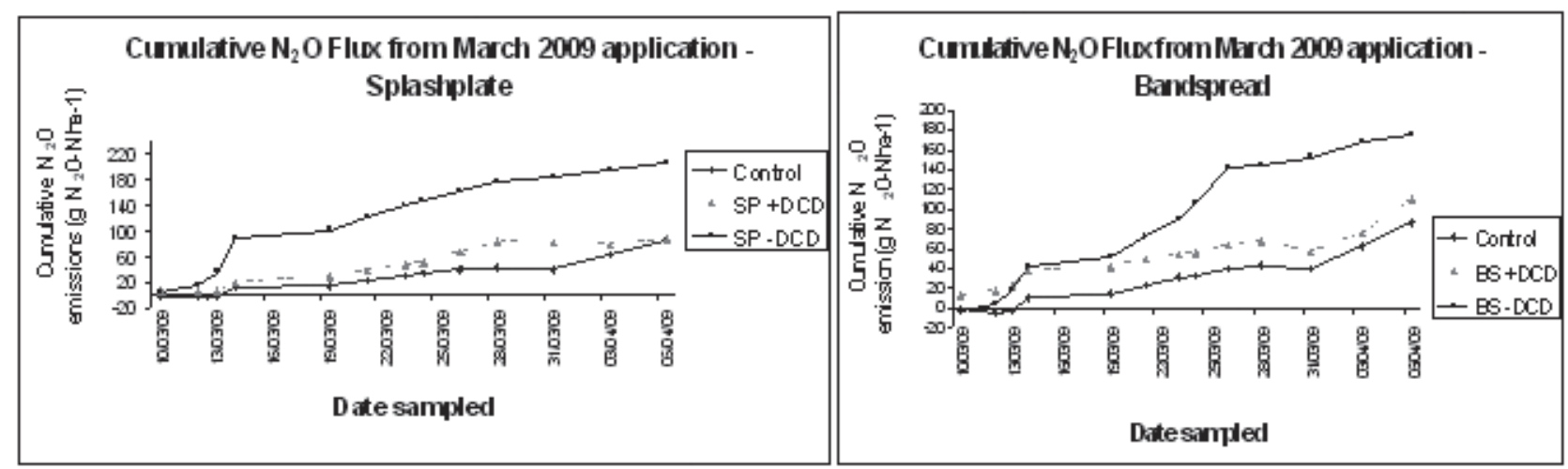

Figure 1 Cumulative daily $\mathrm{N}_{2} \mathrm{O}$ emissions for splash plate and bandspread slurry \pm nitrification inhibitor DCD.

The $\mathrm{N}_{2} \mathrm{O}$ emissions measured over the month after slurry application equated to $\sim 0.2 \%$ of inorganic slurry $\mathrm{N}$ (applied 09/03/09) which is considerably lower than the default emission factor $1 \%$ used by the IPCC. The $\mathrm{N}_{2} \mathrm{O}$ emissions were very similar for the two spreading methods and the inclusion of DCD has significantly reduced cumulative $\mathrm{N}_{2} \mathrm{O}$ emissions.

Conclusions Emission of $\mathrm{N}_{2} \mathrm{O}$ from cattle slurry applied in March was low accounting for about $0.2 \%$ of $\mathrm{N}$ applied. The DCD treatments emitted significantly less $\mathrm{N}_{2} \mathrm{O}$ then both the non-DCD treatment and the control. The incorporation of DCD with the landspread slurry reduced $\mathrm{N}_{2} \mathrm{O}$ emissions by 46 to $62 \%$.

Acknowledgements This research is financially supported under the National Development Plan, through the Research Stimulus Fund, administered by the Department of Agriculture and Food, Ireland.

\section{References}

Dennis, S.J., Richards, K.G., Cameron, K.C., Di, H.J., Moir, J.L., Fay, D., Staples, V. and Sills P. 2008. Agricultural Research Forum Tullamore, Ireland, 12-13 March 2008, 6.

Di, H.J. and Cameron, K.C. 2006. Biology and Fertility of Soils 42, 472-480 